\title{
Heart Team: Joint Position of the Swiss Society of Cardiology and the Swiss Society of Cardiac Surgery
}

\author{
Giovanni B. Pedrazzini ${ }^{1}$ Enrico Ferrari ${ }^{2}$ Michael Zellweger ${ }^{1} \quad$ Michele Genoni $^{2}$ \\ ${ }^{1}$ Swiss Society of Cardiology (SSC), Ticino, Switzerland \\ ${ }^{2}$ Swiss Society of Cardiac Surgery (SGHC), Zurich, Switzerland \\ Thorac Cardiovasc Surg 2017;65:519-523.

\begin{abstract}
Address for correspondence Michele Genoni, Stadtspital Triemli-Klinik für Herzchirurgie, Birmensdorferstr. 497 Zürich 8063, Switzerland (e-mail: michele.genoni@zuerich.ch; daniela.kleemann@zuerich.ch).
\end{abstract}

\begin{abstract}
Keywords

- heart team

- coronary artery disease

- transcatheter aortic valve replacement

The Swiss Society of Cardiology (SSC) and the Swiss Society of Cardiac and Thoracic Vascular Surgery (SSCTVS) have formulated their mutual intent of a close, patient-oriented, and expertise-based collaboration in the Heart Team Paper. The interdisciplinary dialogue between the SSC and SSCTVS reflects an attitude in decision making, which guarantees the best possible therapy for the individual patient. At the same time, it is a cornerstone of optimized process quality, placing individual interests into the background.

Evaluation of the correct indication for a treatment is indeed very challenging and almost impossible to verify retrospectively. Quality in this very important health policy process can therefore only be assured by the use of mutually recognized indications, agreed upon by all involved physicians and medical specialties, whereby the capacity of those involved in the process is not important but rather their competence.

These two medical societies recognize their responsibility and have incorporated international guidelines as well as specified regulations for Switzerland. Former competitors now form an integrative consulting team able to deliver a comprehensive evaluation for patients. Naturally, implementation rests with the individual caregiver. The Heart Team Paperof the SGK and SGHC, has defined guide boards within which the involved specialists maintain sufficient room to maneuver, and patients have certainty of receiving the best possible therapy they require.
\end{abstract}

\section{Introduction}

The role of the modern heart team and its current application in the daily clinical practice have been extensively described in recent guidelines on coronary revascularization edited by the European Society of Cardiology. ${ }^{1}$ Both the Swiss Society of Cardiology (SSC) and the Swiss Society of Cardiac Surgery (SSCC) officially endorse the European guidelines and believe that this novel and evolving approach represents a unique opportunity that all cardiac institutions should be informed about, regardless of their internal organization.

Hence, according to its political implications, the decision has been taken to publish a position article, which would define the role and responsibility of the modern heart team nationwide.

In particular, we will analyze the areas where a concept of modern heart team must be adopted, namely coronary revascularizations, complex structural heart procedures, and heart valve interventions.

received

August 7, 2017

accepted

August 7, 2017

published online

September 18, 2017

\section{The Team Work}

It is widely acknowledged that multidisciplinary and wellorganized team work enhances the quality of care and treatment of patients with specific diseases. At the beginning of the sixties, the creation of a multidisciplinary "Tumor Board" was shown to be associated with an improved survival rate and quality of life in patients with breast cancer. ${ }^{2}$

In cardiovascular care, discussions by heart team of specific patient groups have already been taking place for several years. Typical issues are how to treat congenital heart disease (in both children and adults), to coordinate cardiac transplantation, and more recently, managing end-stage heart failure.

A heart team for coronary disease was first set up to select patients eligible for randomization in clinical trials comparing coronary artery bypass grafting (CABG) with medical therapy for stable angina. ${ }^{3}$ Partly due to the introduction, in the seventies, of percutaneous coronary intervention (PCI),

(c) 2017 Georg Thieme Verlag KG Stuttgart · New York
DOI https://doi.org/ 10.1055/s-0037-1606356. ISSN 0171-6425. 
interventional cardiologists and cardiac surgeons were increasingly treating the same population at risk offering alternative approaches. Randomized clinical trials comparing CABG and percutaneous revascularization followed, in which the two specialties worked closely together to ensure accurate patient selection and to establish well-balanced distribution between the two treatments. ${ }^{4,5}$ Because of its high clinical interest and prognostic relevance, the topic "myocardial revascularization" has been subjected to numerous randomized clinical trials, including as reported in a recent network meta-analysis, globally more than 93,553 patients. ${ }^{6}$

More recently, the advent of transcatheter valve therapies has also emphasized the role of a heart team, including both specialties for screening, managing, and treating heart valve disease using different surgical or interventional approaches according to the individual risk of the patient.

The concept of heart team has been developed and intensified in the last few years. The main goal is to offer a balanced and complementary approach to patient care by joint and shared decision making among different medical care stakeholders, such as cardiac surgery, interventional cardiology, and cardiac imaging. ${ }^{7}$

\section{Heart Team in Context of Coronary Artery Disease}

The new guidelines on myocardial revascularization focus on the importance of the heart team for patients requiring a complex myocardial revascularization, ${ }^{1}$ underlying the medical evidence that an individual stratification of the riskbenefit ratio considerably improves the clinical outcome and prognosis, ${ }^{8,9}$ but also reduces the risk of under (or inappropriate) use of coronary revascularization procedures. ${ }^{10,11}$

In a multidisciplinary evaluation of complex coronary clinical scenarios, that is, left main disease, three-vessel coronary disease, high-risk proximal anterior descending artery lesions, selected patients with depressed left ventricular (LV) function, the role of the heart team is (1) to define the therapeutic goal (prognostic versus symptomatic, complete versus partial coronary revascularization); (2) to establish the best strategy for myocardial revascularization (percutaneous versus surgical versus pharmacological); and (3) to measure the individual procedural risk assessed by specific risk scores.

The specific clinical and anatomic indications, which the heart team should be involved in, have already been analyzed in detail in the modern guidelines on myocardial revascularization, ${ }^{1}$ and therefore, will not be discussed here.

The modern risk scores are based on the analysis of clinical and angiographic predictors evaluated in multicentric studies and registries on coronary revascularization and are recommended as an integrative tool for supporting decisionmaking processes within the heart team. To date, the following well-established surgical scores are recommended for their high reliability: the STS score of the Society of Thoracic Surgeons ${ }^{12}$ and the updated version of the EuroSCORE, the EuroSCORE II. ${ }^{13}$ Among the anatomic scores, the SYNTAX score remains the most used and reliable one despite its complexity and a well-recognized interindividual variability, limiting its daily clinical application. ${ }^{14}$

As suggested by recent recommendations in the case of stable complex coronary artery disease, a noninvasive

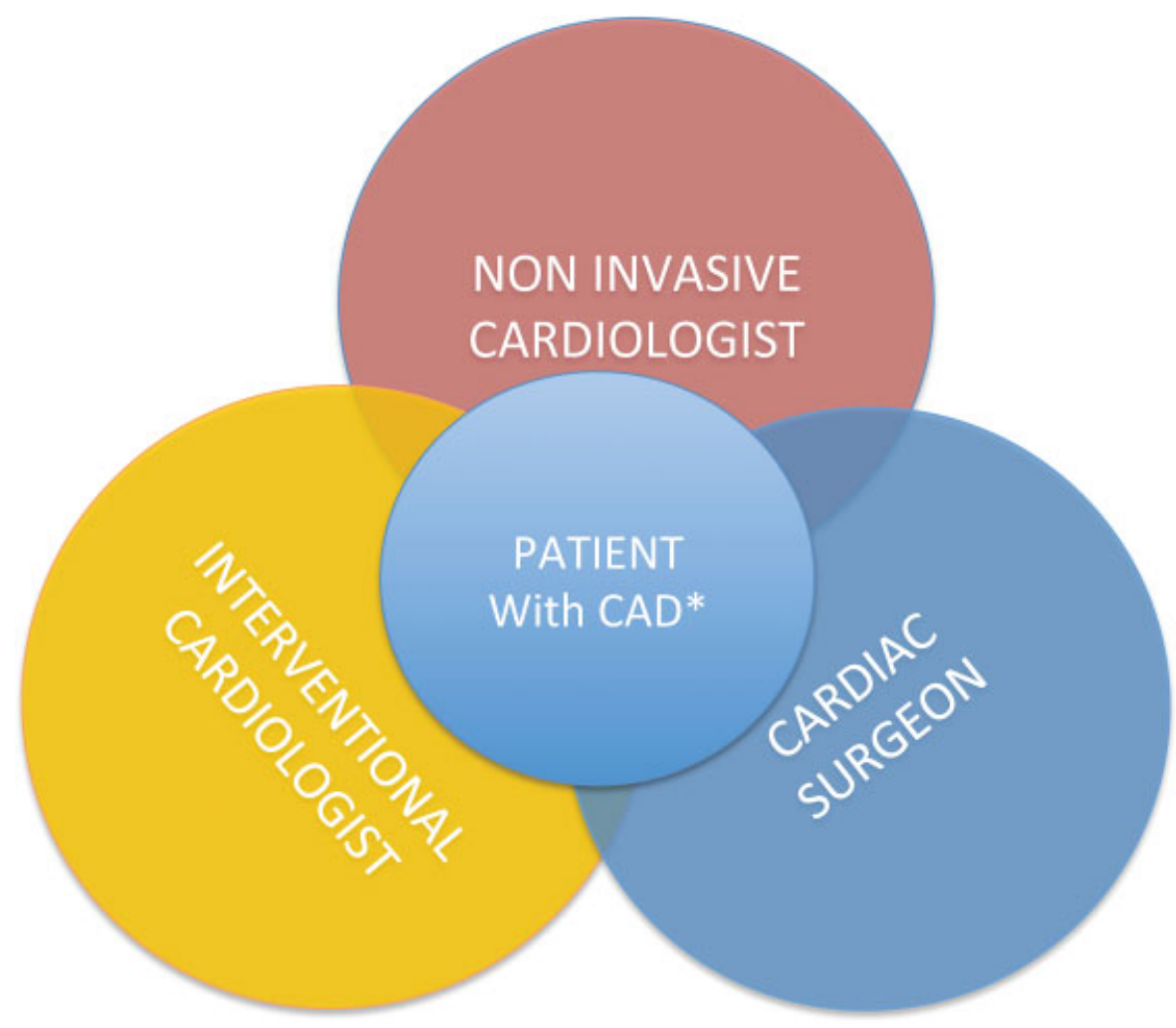

Fig. 1 Heart team in the context of coronary artery disease. CAD*, coronary artery disease. 
cardiologist, an interventional cardiologist, and a cardiac surgeon (the components of the modern heart team for coronary disease) have to be involved together in evaluating whether an optimal medical therapy, a PCI, a coronary artery bypass grafting, or a hybrid approach (simultaneous or differed PCI and (ABG) is the preferred treatment (- Fig. 1). ${ }^{15}$ The heart team decision-making process, while discussing coronary cases (regardless of the physical presence of the patient), has to be based on three important key points: the knowledge transfer, the different treatment options, and the final agreement on the best myocardial revascularization strategy for every single clinical case. ${ }^{15}$ The latter has to be documented in the patient's chart.

\section{Heart Team in Context of Valve Disease}

The introduction of transcatheter valve treatments rapidly changed the scenario of the modern management of heart valve disease, particularly aortic valve stenosis and mitral valve regurgitation. During the last few years, both the number of patients treated by transcatheter approach and the spectrum of indication rapidly expanded, leading to a repetitive update of recommendations for clinical practice. ${ }^{16-20}$ In the decision-making process for patients with advanced heart valve disease requiring treatment, the discussion within the heart team represents an essential, irreplaceable decisional step and is considered by the Swiss
Federal Office of Public Health (FOPH) as one of the mandatory conditions for the final procedural reimbursement (FOPH communication of July 25, 2013).

As strongly recommended by the European and the American guidelines on the management of valvular heart disease, the role of the modern heart team for valve disease is to share and analyze all available patient's information. This information must include clinical-anamnestic data, anatomical details (coronary angiography, 2D-3D echocardiography, computational cardiovascular imaging), and a calculated procedural risk score made by using on-line versions of the STS or EuroSCORE II calculators. ${ }^{21,22}$

All the above will allow the heart team for valve disease to personalize and optimize the final treatment according to the most recent knowledge and recommendations in this rapidly evolving medical field. Every candidate for potential valve intervention has to be discussed within the heart team. The discussion should be based on the following three key points: the knowledge transfer, the discussion of the most effective treatment (percutaneous vs. surgical vs. hybrid vs. conservative), and the final agreement on the treatment recommendation.

The heart team in the context of valve disease consists of a cardiac surgeon, an interventional cardiologist (both experts in this field), an imaging specialist, and if necessary, an anesthesiologist and intensive care specialist ( - Fig. 2). ${ }^{21}$ All members of the heart team for valve disease are strongly committed to

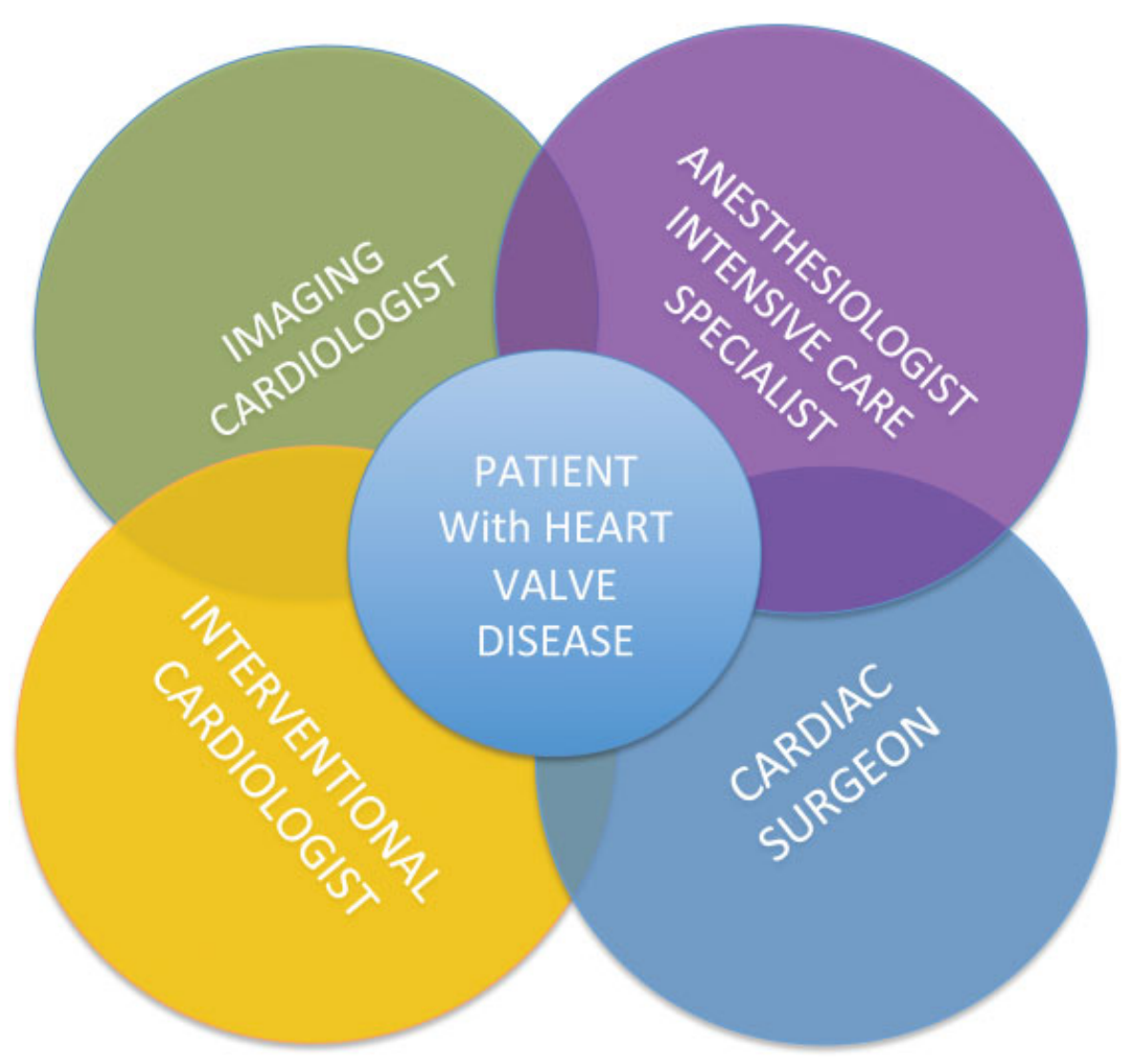

Fig. 2 Heart team in the context of heart valve disease. 
work together and define, for every single patient and every single scheduled procedure, the different team players according to the specific skills and the technical expertise.

\section{Organization and Logistic}

Currently, there exist no rules regarding the organization of a modern heart team. What works well in one institution may not be the optimal approach in another.

Each institution is free to internally define the ways of interactions among the various teams. If the cardiac surgery unit is on site, the clinical cases are usually discussed on a regular basis, or if needed, during "ad hoc" meetings. If the center has no cardiac surgery on site, meetings with cardiac surgeons can be organized via videoconferences or shared images (virtual heart team). Regardless of the internal organization, a high level of interaction and communication is essential between the different teams and within the members of the heart team. Advanced decision-making process should be based on the critical analysis of all available information, including the patient clinical data and evidence-based data from the modern scientific literature.
In Switzerland, 17 interventional institutions also have a cardiac surgery unit on site (5 university hospitals, 4 public hospitals, and 8 private clinics), whereas 20 centers do not (11 public hospitals and 9 private centers, - Fig. 3). Among them, as expected, there are considerable differences in terms of interventional and surgical volume, and so far, there are no specific recommendations about the creation of institutional heart teams in the context of coronary and heart valve disease. Therefore, every center in Switzerland is free to set up its own heart team and is free to manage the way the members of the heart team should interact and communicate. Nevertheless, we believe that strong commitment, open mindedness, adaptability, versatility, and team player capability should be the "must have" skills for every member involved in a modern and dynamic heart team.

The goal of the SCC, the Swiss Society of Cardiac Surgery (SSCC), and the Swiss Working Group on Interventional Cardiology is to underline the importance and the need for each cardiac center to have a multidisciplinary, qualified heart team based on international standards that can offer to the patients and the community a modern, balanced,

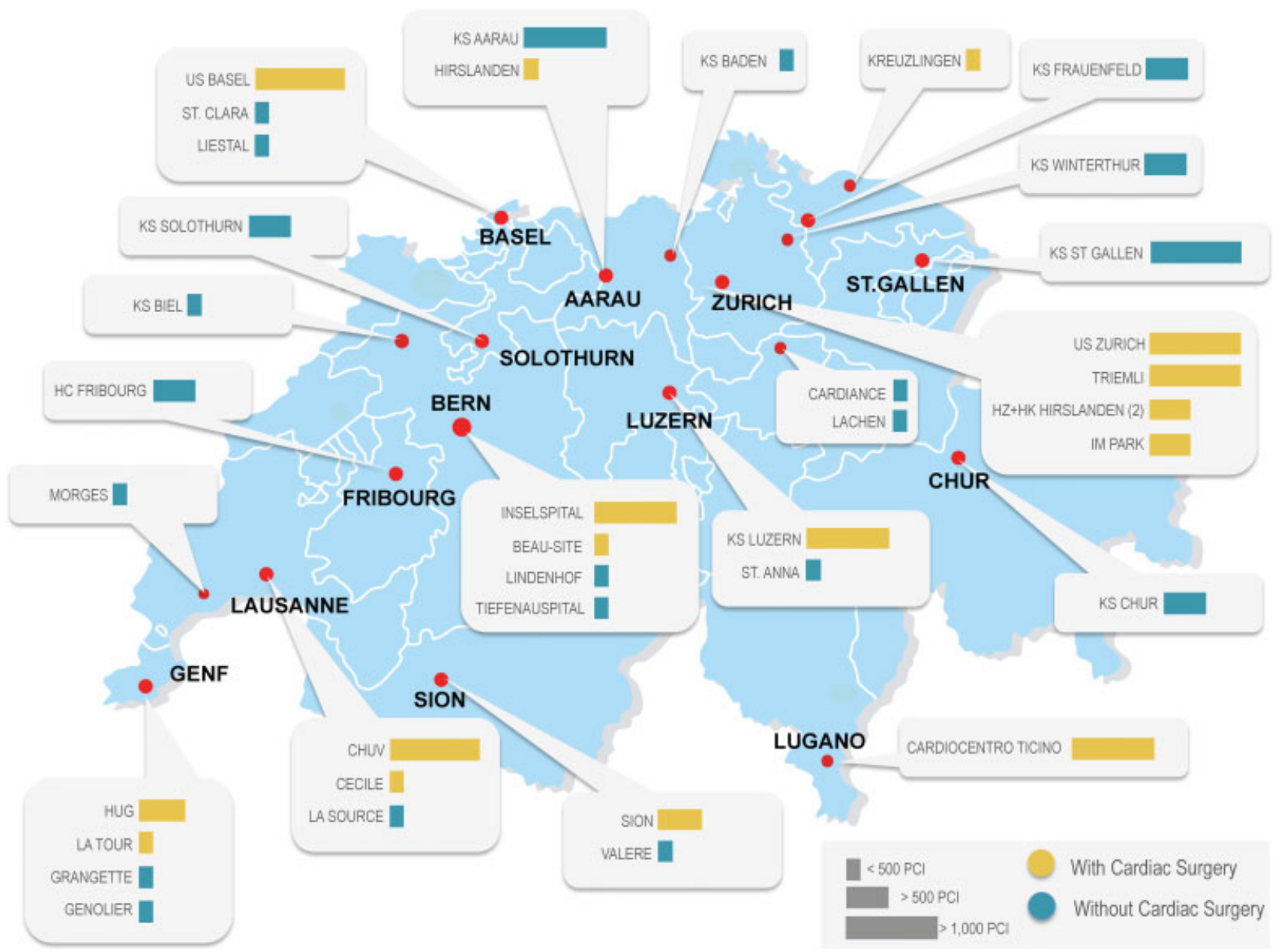

Fig. 3 Geographical distribution of the Swiss interventional cardiology units (dated 2015) classified according to their PCl volume ( $<500,500-$ $100 \mathrm{PCl},>1,000 \mathrm{PCl}$ per year) and the presence of cardiac surgery on site (yellow: with cardiac surgery on site, blue: without cardiac surgery on site). $\mathrm{PCl}$, percutaneous coronary intervention. 
complementary, and individualized approach to complex coronary and valvular heart diseases.

\section{References}

1 Windecker S, Kolh P, Alfonso F, et al; Authors/Task Force members. 2014 ESC/EACTS Guidelines on myocardial revascularization: the task force on myocardial revascularization of the European Society of Cardiology (ESC) and the European Association for CardioThoracic Surgery (EACTS) Developed with the special contribution of the European Association of Percutaneous Cardiovascular Interventions (EAPCI). Eur Heart J 2014;35(37):2541-2619

2 Kesson EM, Allardice GM, George WD, Burns HJ, Morrison DS. Effects of multidisciplinary team working on breast cancer survival: retrospective, comparative, interventional cohort study of 13722 women. BMJ 2012;344:e2718

3 Prospective randomised study of coronary artery bypass surgery in stable angina pectoris. Second interim report by the European Coronary Surgery Study Group. Lancet 1980;2(8193):491-495

4 King SB III, Lembo NJ, Weintraub WS, et al. A randomized trial comparing coronary angioplasty with coronary bypass surgery. Emory Angioplasty versus Surgery Trial (EAST). N Engl J Med 1994;331(16):1044-1050

5 Bypass Angioplasty Revascularization Investigation (BARI) Investigators. Comparison of coronary bypass surgery with angioplasty in patients with multivessel disease. N Engl J Med 1996;335(04): 217-225

6 Windecker S, Stortecky S, Stefanini GG, et al. Revascularisation versus medical treatment in patients with stable coronary artery disease: network meta-analysis. BMJ 2014;348:g3859

7 Holmes DR Jr, Rich JB, Zoghbi WA, Mack MJ. The heart team of cardiovascular care. J Am Coll Cardiol 2013;61(09):903-907

8 Shortell SM, Jones RH, Rademaker AW, et al. Assessing the impact of total quality management and organizational culture on multiple outcomes of care for coronary artery bypass graft surgery patients. Med Care 2000;38(02):207-217

9 Long J, Luckraz H, Thekkudan J, Maher A, Norell M. Heart team discussion in managing patients with coronary artery disease: outcome and reproducibility. Interact Cardiovasc Thorac Surg 2012;14(05):594-598

10 Filardo G, Maggioni AP, Mura G, et al. The consequences of underuse of coronary revascularization; results of a cohort study in Northern Italy. Eur Heart J 2001;22(08):654-662

11 Yates MT, Soppa GK, Valencia O, Jones S, Firoozi S, Jahangiri M. Impact of European Society of Cardiology and European Association for Cardiothoracic Surgery Guidelines on Myocardial Revascularization on the activity of percutaneous coronary intervention and coronary artery bypass graft surgery for stable coronary artery disease. J Thorac Cardiovasc Surg 2014;147(02): 606-610

12 Shahian DM, O'Brien SM, Filardo G, et al; Society of Thoracic Surgeons Quality Measurement Task Force. The Society of Thoracic Surgeons 2008 cardiac surgery risk models: part 3-valve plus coronary artery bypass grafting surgery. Ann Thorac Surg 2009;88 (1, Suppl)S43-S62

13 Nashef SA, Roques F, Sharples LD, et al. EuroSCORE II. Eur J Cardiothorac Surg 2012;41(04):734-744; discussion, 744-745

14 Mohr FW, Morice MC, Kappetein AP, et al. Coronary artery bypass graft surgery versus percutaneous coronary intervention in patients with three-vessel disease and left main coronary disease: 5 -year follow-up of the randomised, clinical SYNTAX trial. Lancet 2013;381(9867):629-638

15 Head SJ, Kaul S, Mack MJ, et al. The rationale for Heart Team decision-making for patients with stable, complex coronary artery disease. Eur Heart J 2013;34(32):2510-2518

16 Kapadia SR, Leon MB, Makkar RR, et al; PARTNER trial investigators. 5-year outcomes of transcatheter aortic valve replacement compared with standard treatment for patients with inoperable aortic stenosis (PARTNER 1): a randomised controlled trial. Lancet 2015;385(9986):2485-2491

17 Mack MJ, Leon MB, Smith CR, et al; PARTNER 1 trial investigators. 5 -year outcomes of transcatheter aortic valve replacement or surgical aortic valve replacement for high surgical risk patients with aortic stenosis (PARTNER 1): a randomised controlled trial. Lancet 2015;385(9986):2477-2484

18 Cribier A, Durand E, Eltchaninoff $\mathrm{H}$. Patient selection for TAVI in 2014: is it justified to treat low- or intermediate-risk patients? The cardiologist's view. EuroIntervention 2014;10(Suppl U): U16-U21

19 Leon MB, Smith CR, Mack MJ, et al; PARTNER 2 Investigators. Transcatheter or surgical aortic-valve replacement in intermediate-risk patients. N Engl J Med 2016;374(17):1609-1620

20 Maisano F, Alfieri O, Banai S, et al. The future of transcatheter mitral valve interventions: competitive or complementary role of repair vs. replacement? Eur Heart J 2015;36(26):1651-1659

21 Nishimura RA, Otto CM, Bonow RO, et al; American College of Cardiology; American College of Cardiology/American Heart Association; American Heart Association. 2014 AHA/ACC guideline for the management of patients with valvular heart disease: a report of the American College of Cardiology/American Heart Association Task Force on Practice Guidelines. J Thorac Cardiovasc Surg 2014;148(01):e1-e132

22 Vahanian A, Alfieri O, Andreotti F, et al; Joint Task Force on the Management of Valvular Heart Disease of the European Society of Cardiology (ESC); European Association for Cardio-Thoracic Surgery (EACTS). Guidelines on the management of valvular heart disease (version 2012). Eur Heart J 2012;33(19):2451-2496 